\title{
A Molecular Dynamic Simulation of Hydrated Proton Transfer in Perfluorosulfonate Ionomer Membranes (Nafion 117)
}

\author{
Hong Sun, ${ }^{1}$ Mingfu Yu, ${ }^{1}$ Zhijie Li, ${ }^{1}$ and Saif Almheiri ${ }^{2}$ \\ ${ }^{1}$ Department of Transportation and Mechanical Engineering, Shenyang Jianzhu University, Shenyang 110168, China \\ ${ }^{2}$ Institute Center for Energy (iEnergy), Masdar Institute of Science and Technology, P.O. Box 54224, Abu Dhabi, UAE \\ Correspondence should be addressed to Hong Sun; sunhongwxh@sina.com
}

Received 30 September 2014; Accepted 7 December 2014

Academic Editor: DuuJong Lee

Copyright (C) 2015 Hong Sun et al. This is an open access article distributed under the Creative Commons Attribution License, which permits unrestricted use, distribution, and reproduction in any medium, provided the original work is properly cited.

\begin{abstract}
A molecular dynamic model based on Lennard-Jones Potential, the interaction force between two particles, molecular diffusion, and radial distribution function (RDF) is presented. The diffusion of the hydrated ion, triggered by both Grotthuss and vehicle mechanisms, is used to study the proton transfer in Nafion 117. The hydrated ion transfer mechanisms and the effects of the temperature, the water content in the membrane, and the electric field on the diffusion of the hydrated ion are analyzed. The molecular dynamic simulation results are in good agreement with those reported in the literature. The modeling results show that when the water content in Nafion 117 is low, $\mathrm{H}_{3} \mathrm{O}^{+}$is the main transfer ion among the different hydrated ions. However, at higher water content, the hydrated ion in the form of $\mathrm{H}^{+}\left(\mathrm{H}_{2} \mathrm{O}\right)_{2}$ is the main transfer ion. It is also found that the negatively charged sulfonic acid group as the fortified point facilitates the proton transfer in Nafion 117 better than the free water molecule. The diffusion of the hydrated ion can be improved by increasing the cell temperature, the water content in Nafion, and the electric field intensity.
\end{abstract}

\section{Introduction}

There is no doubt that fuel cell technologies have reached a point in the commercialization stage in which they started to replace conventional sources to power automobiles and mobile devices. However, there are still challenges that need to be addressed, namely, the resistance to cation transfer in proton exchange membranes (PEMs) that contributes significantly to the impedance of the cell. For low temperature PEM fuel cells (PEMFCs), perfluorosulfonate membrane (Nafion) is commonly used as a proton exchange membrane. Understanding the proton transfer mechanism in Nafion membranes is very important in order to achieve solutions that can mitigate the electrolyte resistance.

There are two main mechanisms that are used to describe the proton transfer in a proton exchange membrane, namely, the Grotthuss mechanism (hopping mechanism) and the ordinary en masse diffusion (vehicle mechanism). In the Grotthuss mechanism, a proton hops from one point to the next along the hydrogen-bond network. For example, in a Nafion membrane, a proton hops from a donor acid site to a nearby acceptor water molecule. In contrast, in the vehicle mechanism, a proton transfers by the diffusion of carrier species in the electrolyte in the form of a hydrated ion. Both of the two mechanisms were studied in the literature and other mechanisms were also proposed.

Karo et al. [1], based on the Grotthuss mechanism, investigated the residence times for water molecules around the end groups in Nafion and Hyflon. The group found that Hyflon displays a lower degree of phase separation than Nafion. Moilanen et al. [2] found via ultrafast infrared spectroscopy that the hydrophilic domains of Nafion grow with increased hydration. Based on the Grotthuss mechanism, it has been found [3] that an environment that is favorable for the Grotthuss-like effective proton transport process is favorable for water transfer in the presence of a homogeneous electric field. The water bridges developed by free water molecules are considered as the passage for proton transfer from one sulfonic group to its adjacent sulfonic group in perfluorinated sulfonic acid polytetrafluoroethylene by dissociation and separation of proton from the sulfonic acid group [4-6]. Choi et al. presented a comprehensive pore transport model to 


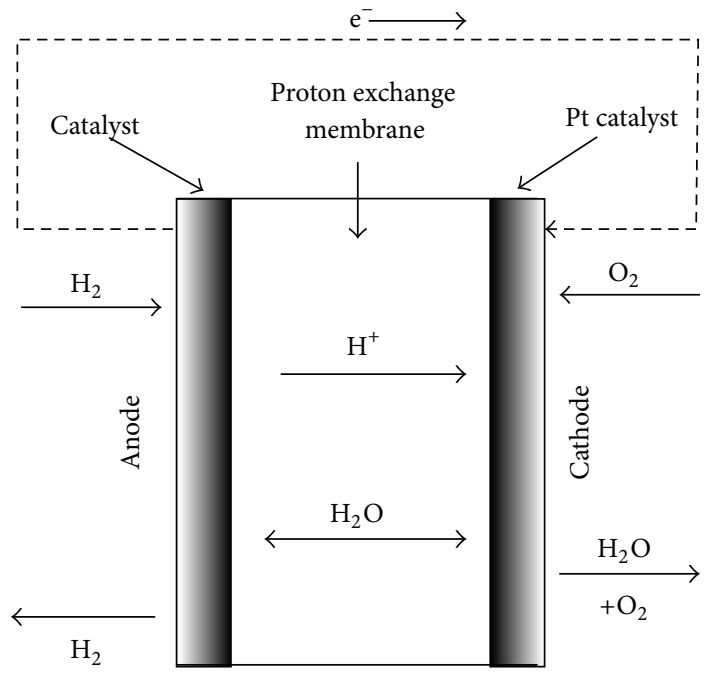

(a) Fuel cell structure

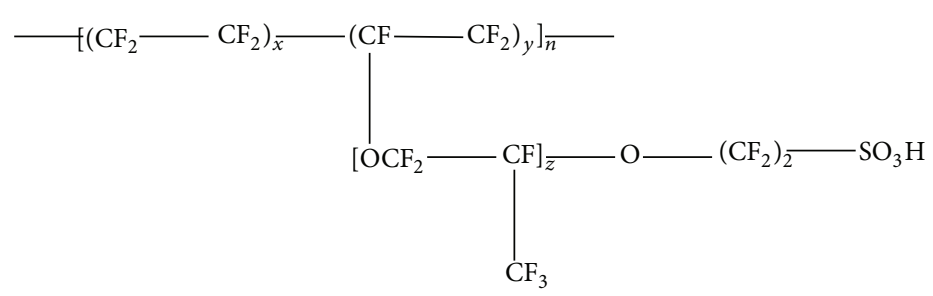

(b) Chemical structure of Nafion 117

FIgURE 1: The structure of fuel cell and chemical structure of Nafion 117 membrane.

study various proton transfer mechanisms, specifically proton hopping along surface, Grotthuss diffusion, and ordinary mass diffusion of hydronium ions [7].

An example of a work done to explore the vehicle mechanism of proton transfer in aqueous phase structure is the molecular dynamic simulations done by Keffer et al. [8] on Nafion polyelectrolyte membrane. Additionally, the vehicular transport of hydronium ions and water molecules was investigated using classical molecular dynamics simulations in [9]. Jayakody et al. [10] studied the self-diffusion of water in Nafion 117 as a function of pressure and found that the transport mechanism in a membrane with high water content is similar to that in liquid bulk water. Jinnouchi and Okazaki [11] suggested that the low diffusivity in the Nafion membrane is due to polar particles forming a disordered heterogeneous structure of the hydrophilic region.

No matter what kind of proton transfer mechanism is used or proposed, it is always of importance to understand the factors that affect the dynamics of the water molecules, the carriers. Han et al. [12] found via ab initio simulations that $\mathrm{H}_{5} \mathrm{O}_{2}{ }^{+}$with high mobility in water plays a significant role in proton transfer. Intharathep et al. [13] concluded that $\mathrm{H}_{9} \mathrm{O}_{4}{ }^{+}$ frequently converts back and forth into $\mathrm{H}_{5} \mathrm{O}_{2}{ }^{+}$. Kaledin et al. [14] investigated the prominent spectral feature of $\mathrm{H}_{5} \mathrm{O}_{2}{ }^{+}$by calculating the infrared spectrum. To study proton salvation and proton mobility in water, the hydration shells of $\mathrm{H}_{3} \mathrm{O}^{+}$were investigated by using the multistate empirical valence-bond methodology in [15] $\mathrm{H}_{3} \mathrm{O}^{+}$is considered as another carrier of proton; it has been found [16] that the diffusion coefficient of a $\mathrm{H}_{3} \mathrm{O}^{+}$cation increases with increase of the hydration level. For hydrated Nafion, it has been demonstrated that the average lifetime of $\mathrm{H}_{3} \mathrm{O}^{+}$is close to the lowest limit; furthermore, $-\mathrm{SO}_{3} \mathrm{H}$ directly and indirectly aids in the formation of proton, $-\mathrm{SO}_{3}{ }^{-}$and $-\mathrm{SO}_{3} \mathrm{H}_{2}{ }^{+}$[17].

The cell temperature, the water content in the membrane, and the electric field are the main factors that influence the proton transfer. The increases of the operating temperature and the water content in Nafion improve the proton transfer [18-23]. Spry and Fayer [24] investigated the proton concentration in the center of the water pools in Nafion by HPTS. For lower starting water contents in Nafion 117, the low temperature conductivity decreases rapidly with water contents [25]. In the Nafion 112, 115, 1110, and 1123 membranes, water sorption did not scale with the membrane thickness; it was found that the rate of water desorption was an order of magnitude higher than that of water sorption [26]. In addition to temperature and water content, platinum and electric field have their effect on proton transfer as well. At lower water contents, water is strongly attracted to platinum, resulting in increasing the density near the surface of platinum nanoparticles [27]. The proton carried by the hydronium transfers in the direction of the applied electric field [28]. Brandell et al. [29] found that the structural differences among Nafion, Dow, and Aciplex membranes affect the proton mobility at high hydration levels.

In this work, a molecular dynamic model with LennardJones Potential, the interaction force between two particles, molecular diffusion, and radial distribution function (RDF) is presented. The diffusion of the hydrated ion, triggered by both Grotthuss and vehicle mechanisms, is used to describe the proton transfer in Nafion 117. The RDF is used to study the proton's carrier and its fortified point. The canonical (NVT) system, Andersen hot bath method, and Verlet leapfrog algorithm are used in the computations. The effects of the temperature, the water content, and the electric field on the diffusion of the hydrated ion are analyzed.

\section{Model Description}

Before proceeding with the model, the structure of PEM fuel cell and the chemical structure of Nafion 117 are depicted in Figure 1. The PEM fuel cell in Figure 1(a) consists of 
electrodes and proton exchange membrane. Nafion 117 is used as the proton exchange membrane. The chemical structure of Nafion 117 is shown in Figure 1(b), where $x$ varies from 6 to $10, y=1$, and $z=1$.

In this work, the molecular system consists of 2 long Nafion 117 chains, 20 hydronium cations, and several water molecules. The number of water molecules is determined by the water content $(\lambda)$ in the membrane defined as

$$
\lambda=\frac{n_{\mathrm{H}_{2} \mathrm{O}}}{n_{\mathrm{SO}_{3}{ }^{-}}}
$$

where $n_{\mathrm{H}_{2} \mathrm{O}}$ is the number of the water molecules and $n_{\mathrm{SO}_{3}{ }^{-}}$is the number of the sulfonate groups.

The energy of interaction $\left(\mathscr{V}^{i j}\right)$ between two particles, $i$ and $j$, in a molecular system can be evaluated by LennardJones Potential:

$$
\mathscr{V}_{i j}=4 \varepsilon_{i j}\left[\left(\frac{\sigma_{i j}}{r_{i j}}\right)^{12}-\left(\frac{\sigma_{i j}}{r_{i j}}\right)^{6}\right],
$$

where $2^{1 / 6} \sigma_{i j}$ and $\varepsilon_{i j}$ give the location $r_{i j}$ and the depth of the potential minimum, respectively; $\sigma_{i j}$ is the distance at which the intermolecular potential energy is zero. Note that $\sigma_{i j}$ and $\varepsilon_{i j}$ are different for different interacting particles.

Based on the Lennard-Jones Potential, the force acting on the $i$ th particle in the $x$ direction can be calculated as

$$
F_{i}^{x}=\sum_{i=1}^{N-1} \sum_{j>i}^{N} \frac{24 \varepsilon_{i j}}{r_{i j}^{2}}\left[2\left(\frac{\sigma_{i j}}{r_{i j}}\right)^{12}-\left(\frac{\sigma_{i j}}{r_{i j}}\right)^{6}\right]\left(x_{i}-x_{j}\right) .
$$

A similar expression can be used for the interaction forces in the $y$ and $z$ directions.

Because of the dynamic molecular system, the position of particle $i$ changes continually. In this model, the mean square displacement (MSD) is used to describe the position of a particle with respect to time:

$$
\operatorname{MSD}(t)=\left\langle\left|r_{i}(t)-r_{i}(0)\right|^{2}\right\rangle,
$$

where $r_{i}(0)$ is the initial position and $r_{i}(t)$ is the position at time $t$.

To describe the diffusion in this system, Einstein's law of diffusion is used as follows:

$$
\lim _{t \rightarrow \infty} \operatorname{MSD}(t)=6 D_{i} t
$$

where $D_{i}$ is the self-diffusivity of a particle. In equilibrium molecular dynamics, $D_{i}$ is calculated using the slope of the MSD at sufficiently long time:

$$
D_{i}=\frac{1}{6 N} \lim _{t \rightarrow \infty} \frac{d}{d t} \sum_{i=1}^{N} \operatorname{MSD}(t)
$$

where $N$ is the total number of particles in the system. Setting $a$ as the slope of the mean square displacement, (5) is simplified as follows:

$$
D_{i}=\frac{a}{6}
$$

TABLE 1: Values of the operating conditions used in the simulation.

\begin{tabular}{lcc}
\hline Temperature $(\mathrm{K})$ & Water content $(\lambda)$ & $\begin{array}{c}\text { Electric field intensity } \\
\left(\times 10^{3} \mathrm{Vm}^{-1}\right)\end{array}$ \\
\hline 293 & 3 & 1 \\
313 & 8 & 3 \\
333 & 15 & 5 \\
353 & 22 & 7 \\
\hline
\end{tabular}

The radial distribution function (RDF) gives the ratio between the local density and the total average density in a system. It also describes the probability of finding a particle in the vicinity of a reference point. The maximum value of the $\mathrm{RDF}$ indicates the highest probability of finding a particle at the corresponding distance $r$. The RDF $(g(r))$ is given by

$$
g(r)=\frac{1}{\rho 4 \pi r^{2} \Delta r} \frac{\sum_{t=1}^{T} \sum_{j=1}^{N} \Delta N(r \longrightarrow r+\Delta r)}{N \times T},
$$

where $T$ is the total time of computation and $\Delta N$ is the number of particles $j$ around $i$ within a shell from $r$ to $r+\Delta r$.

The molecular model was developed in Materials Studio (Accelrys Inc.). The COMPASS (Condensed-phase Optimized Molecular Potentials for Atomistic Simulation Studies) force field was applied to the cell and Ewald Summation Method was adopted to compute the electrostatic interactions between two particles. In this simulation, the effects of temperature, water content, and electric field intensity on proton transfer in a Nafion 117 membrane were studied. The simulation conditions/parameters are given in Table 1. Please note that when the effects of temperature and $\lambda$ were studied, the electric field intensity was set to 0 . When the effect of the electric field intensity was simulated, $\lambda$ and the temperature were set to 8 and $333 \mathrm{~K}$, respectively.

To minimize the energy of this molecular system, an optimization of the cellular structure was carried out by the Smart Minimizer Method. Figures 2 and 3 show the change of energy and temperature during the optimization process. In these figures, $\lambda$ was set to 15 . Once the temperature and the energy of the system reached the desired stability, the system was considered as optimal system. The dynamic computations were performed with the canonical (NVT) ensemble, Andersen Thermostat method was employed to control the system's temperature, and Verlet leap-frog algorithm was used to numerically integrate the equations of motion.

\section{Results and Discussions}

3.1. Proton Transfer Mechanism in Nafion 117. The distributions of different pairs of particles in the system are shown by the RDF in Figure 4. In this figure, the oxygen atom in the free water molecule is marked as $\mathrm{O}_{2}$, the oxygen atom in the hydrated ion is labeled as $\mathrm{O}_{3}, \mathrm{~F}$ denotes the fluorine atom, and $\mathrm{S}$ refers to the sulfur atom. It can be seen that the distance of the most probable appearance between the sulfur atom in the sulfonate group and the oxygen atoms in the free water molecule $\left(\mathrm{S}-\mathrm{O}_{2}\right)$, as well as the hydrated ion $\left(\mathrm{S}-\mathrm{O}_{3}\right)$, is $0.375 \mathrm{~nm}$ and $0.370 \mathrm{~nm}$, respectively. Figure 4 


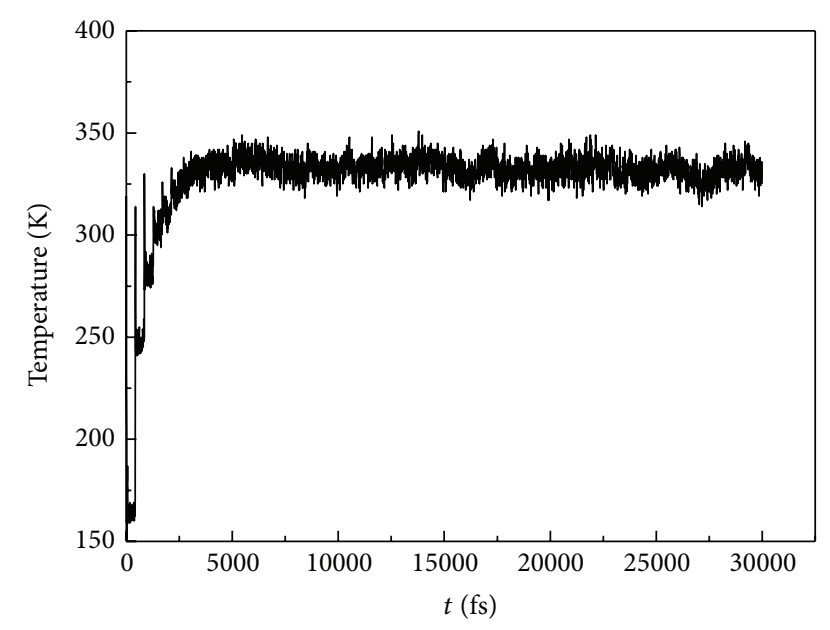

FIGURE 2: Temperature with the system optimization.

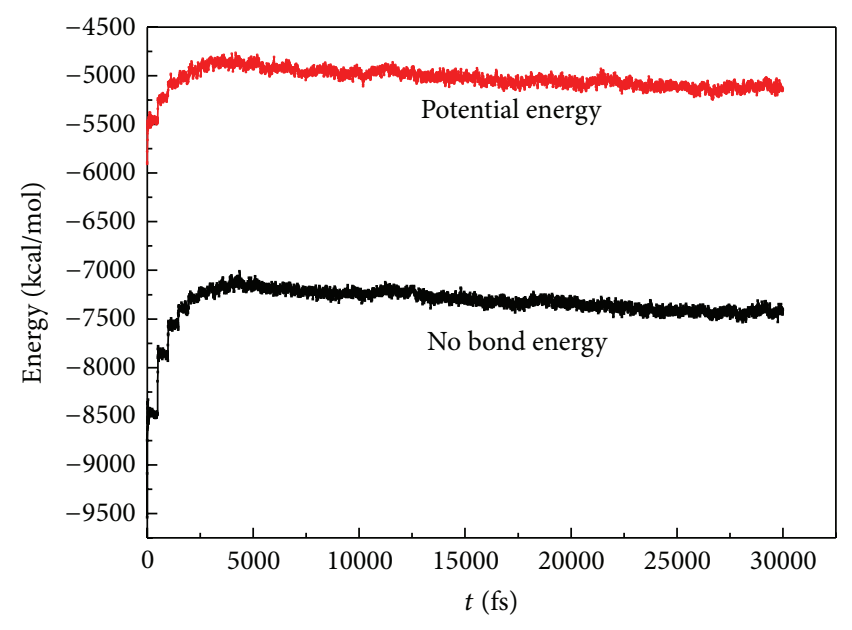

FIGURE 3: Energy with the system optimization.

also shows that the probability of oxygen atom in the free water molecule to appear around the fluorine atom in the side chain of Nafion 117 membrane has no maximum value because fluorine is hydrophobic and, therefore, it repels the water molecule. On the other hand, the sulfonate group in the membrane is hydrophilic; that is, it attracts water molecules. When a hydrogen atom separates from the sulfonic acid group, the group will carry a negative charge. Because of the negative charge, the hydrated ion with the positive charge is more attracted to the sulfonate group when compared to the free water molecule. As a result, the hydrogen atom in the hydrated ion forms a weak bond with the oxygen atom in the sulfonate group. Therefore, the hydrated ion is closer to the sulfonic acid group than the free water molecule.

It is also shown that the distance of the most probable appearance between two adjacent free water molecules $\left(\mathrm{O}_{2}-\right.$ $\mathrm{O}_{2}$ ) is $0.275 \mathrm{~nm}$ and that between hydrated ion and its adjacent free water molecule $\left(\mathrm{O}_{2}-\mathrm{O}_{3}\right)$ is $0.255 \mathrm{~nm}$. It is well known that, for proton transfer in Nafion 117, a proton from the anode side that is close to a water molecule forms a hydrated ion by a weak hydrogen bond with an oxygen atom.

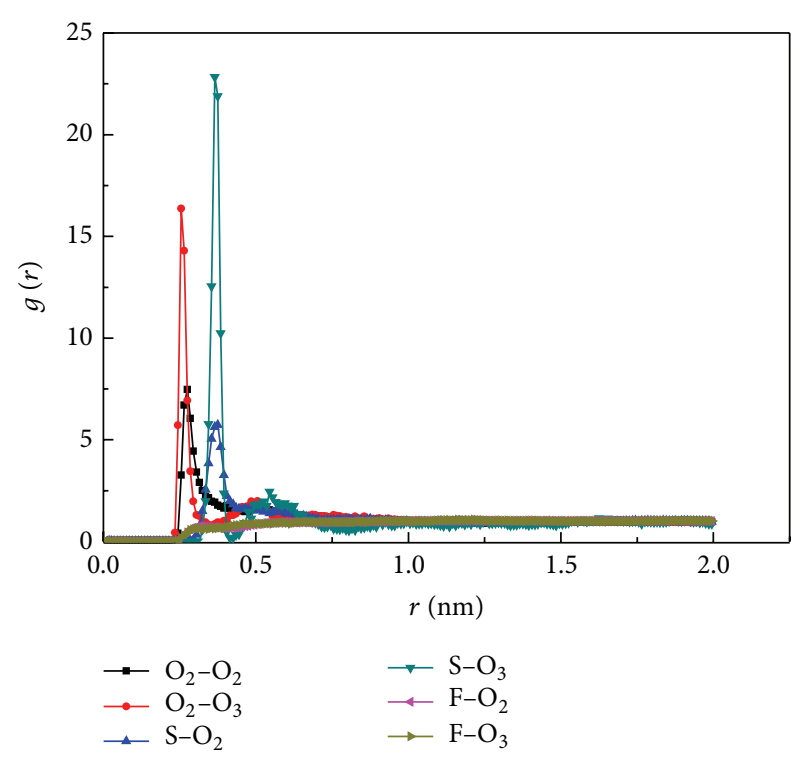

FIGURE 4: The RDFs of different pairs of particles (see legend) at $\lambda=8$ and $T=333 \mathrm{~K}$.

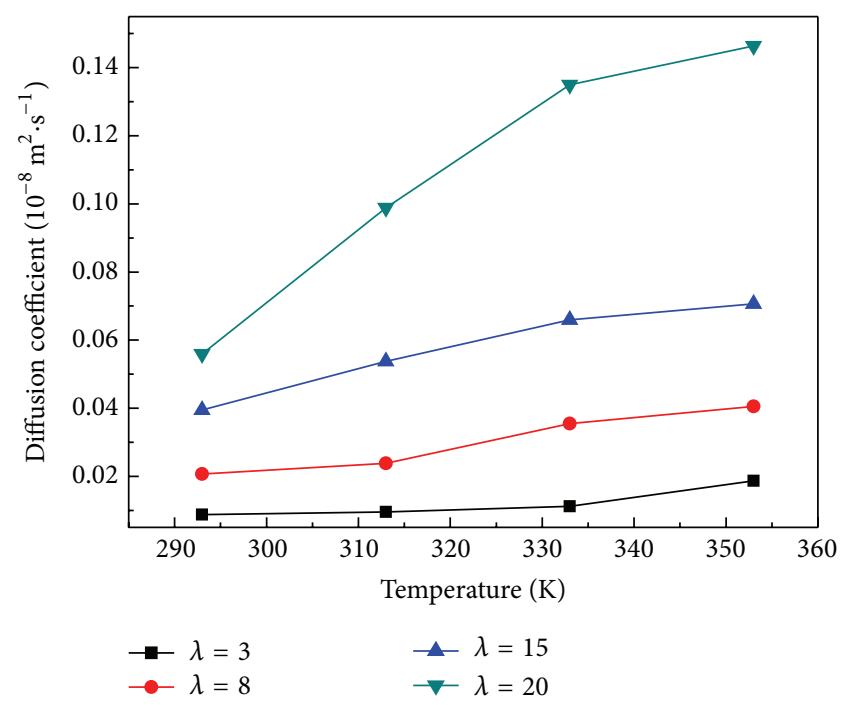

FIGURE 5: The variations in the diffusion coefficient of hydrated ion with the cell temperature at different water contents $(\lambda s)$.

The lesser distance of $\mathrm{O}_{2}-\mathrm{O}_{3}$ than that of $\mathrm{O}_{2}-\mathrm{O}_{2}$ shows that the hydrated ion forms a group with its adjacent water molecule by the hydrogen atom with the positive charge called proton. Therefore, this positively charged hydrogen atom (proton) forms two weak hydrogen bonds with its two adjacent oxygen atoms in the free water molecules. And then, the structure of $\mathrm{H}\left(\mathrm{H}_{2} \mathrm{O}\right)_{2}{ }^{+}$is considered as one of the elementary particles for the hydrated ion transfer in Nafion 117 [12-14].

3.2. Effects of Temperature on the Transfer of the Hydrated Ion. The operating temperature plays a significant role in the transfer of protons through proton exchange membranes. Figure 5 displays the effects of changing the cell temperature 

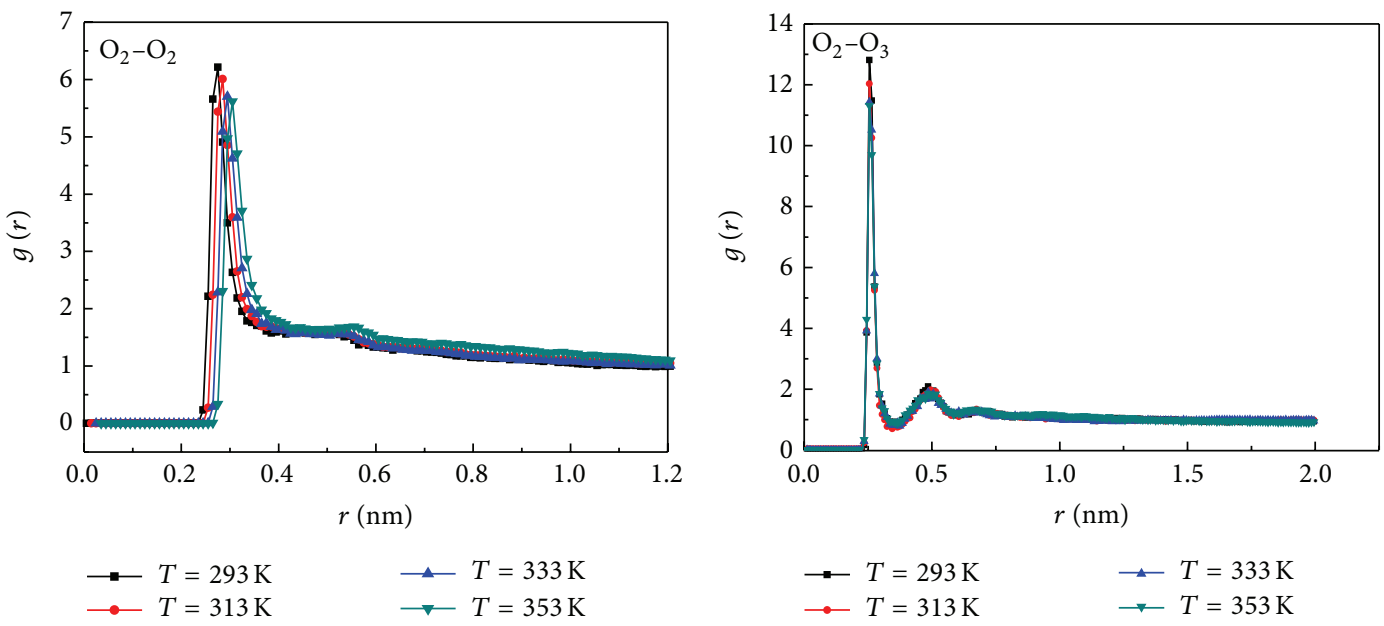

(b) $\mathrm{RDF}$ of $\mathrm{O}_{2}-\mathrm{O}_{3}$ with the temperature
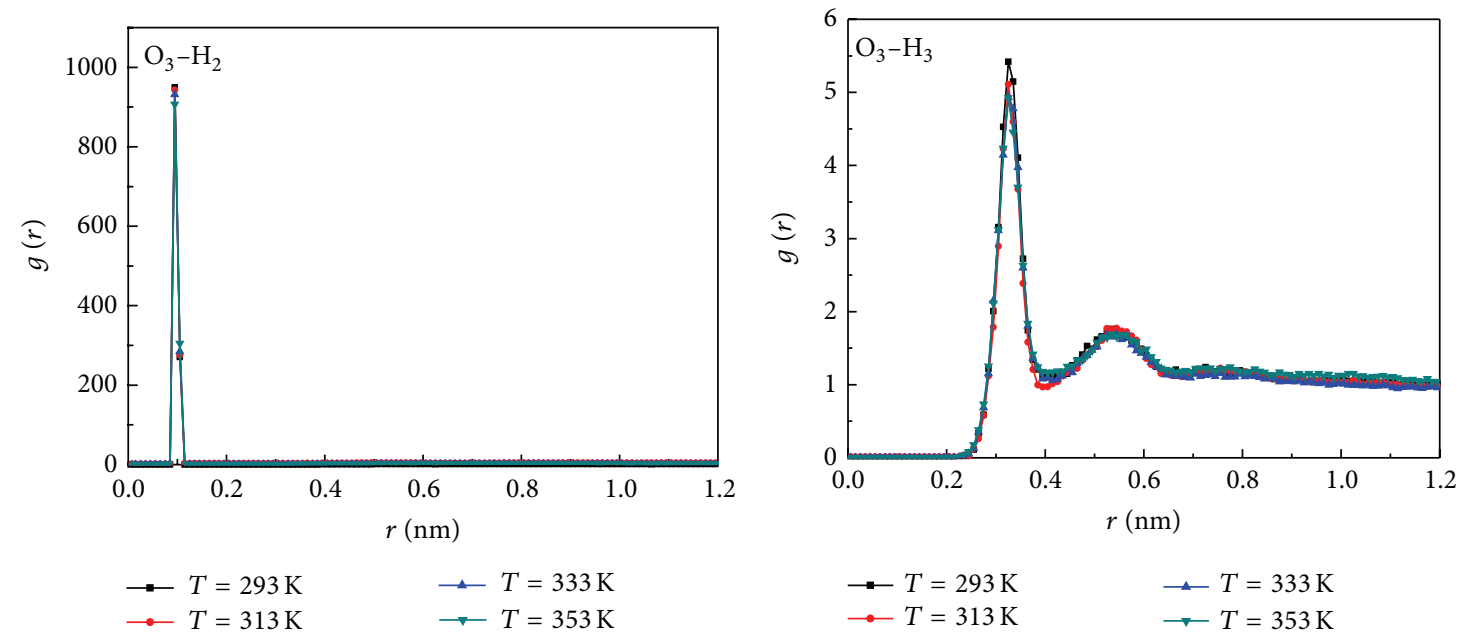

(c) $\mathrm{RDF}$ of $\mathrm{O}_{3}-\mathrm{H}_{2}$ with the temperature

(d) $\mathrm{RDF}$ of $\mathrm{O}_{2}-\mathrm{H}_{3}$ with the temperature

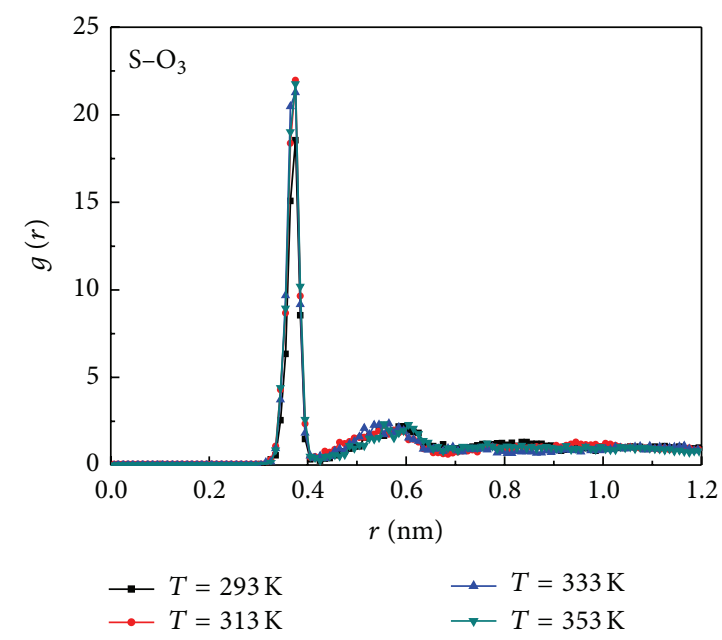

(e) $\mathrm{RDF}$ of $\mathrm{S}_{-} \mathrm{O}_{3}$ with the temperature

FIGURE 6: The RDFs of different pairs of particles at different cell temperatures with $\lambda=8$ and $0 \mathrm{~V} \mathrm{~m}^{-1}$. 
on the diffusion of proton in Nafion 117. It is clear from the figure that the diffusion coefficient of the hydrated ion increases with the increase of the temperature. The reason for this is that higher temperatures promote the movements of the hydrated ions, leading to higher diffusion coefficients. These simulation results have a similar trend to the ones reported in literatures [22, 25].

To further elaborate on the effects of temperature on the diffusion of hydrated ion, the effects of temperature on the structures of all mobile groups in Nafion 117 are depicted in Figure 6 . In this figure, $\lambda$ is set to 8 , the electric field intensity is zero, $\mathrm{H}_{2}$ is the hydrogen atom in the free water molecule, and $\mathrm{H}_{3}$ is the proton diffusing from the anode. It can be seen in Figure 6 that the RDFs of all pairs of particles except for that of $\mathrm{O}_{3}-\mathrm{H}_{2}$ decrease with the increase in temperature. This is because the moving field of these particles gets enlarged with the increase of the moving speed, resulting in the decrease of the local density of the particle. The RDF is the rate of the local density and the total average density. When its numerator decreases and its denominator keeps constant, the RDF value decreases. However, in the free water molecule, the $\mathrm{RDF}$ of its hydrogen atom around its oxygen atom hardly changes due to the strong bond between the two atoms. It is also displayed in Figure 6 that the distances of the most probable appearances (the RDF peak) of $\mathrm{O}_{2}-\mathrm{O}_{3}, \mathrm{O}_{3}-$ $\mathrm{H}_{3}, \mathrm{O}_{3}-\mathrm{H}_{2}$, and $\mathrm{S}-\mathrm{O}_{3}$ barely change with the temperature, while that of $\mathrm{O}_{2}-\mathrm{O}_{2}$ increases because higher temperatures accelerate the movements of the particles. When the kinetic energy of a free water molecule is greater than the exerted binding energy by another free water molecule, its moving field enlarges causing the distance between two adjacent particles to increase. This shows that $\mathrm{O}_{2}-\mathrm{O}_{3}, \mathrm{O}_{3}-\mathrm{H}_{3}, \mathrm{O}_{3}-$ $\mathrm{H}_{2}$, and $\mathrm{S}-\mathrm{O}_{3}$ are probably contained within their respective groups by some internal binding force because of the greater stability shown by these groups when compared to $\mathrm{O}_{2}-\mathrm{O}_{2}$.

3.3. Effects of Water Content ( $\lambda$ ) on the Transfer of the Hydrated Ion. The effects of varying the water content on the diffusion coefficient of the hydrated ion in Nation 117 at different operating temperatures are presented in Figure 7. It is revealed that the hydrated ion diffusion coefficient increases with the increase of the water content. Since water is the carrier of proton transfer in Nafion membranes, increasing the water content provides more proton carriers to the cell, which leads to the decrease of proton transfer resistance in this membrane. These results are similar to those reported in the literatures [19-21].

The RDFs of different pairs of particles at different water contents were calculated in order to further understand the effects of varying the water content on the diffusion coefficient of the hydrated ion; the results are shown in Figure 8 . The calculations were done at a temperature set at $333 \mathrm{~K}$ and an electric field intensity fixed at zero. It can be seen that the maximum RDF values of $\mathrm{O}_{2}-\mathrm{O}_{2}, \mathrm{O}_{2}-\mathrm{O}_{3}$, and $\mathrm{S}-\mathrm{O}_{3}$ decrease with the increase of the water content. When the water content in Nafion 117 increases, the total average density increases, while the local density hardly changes; this leads to the decrease of the maximum value of the $\mathrm{RDF}$.

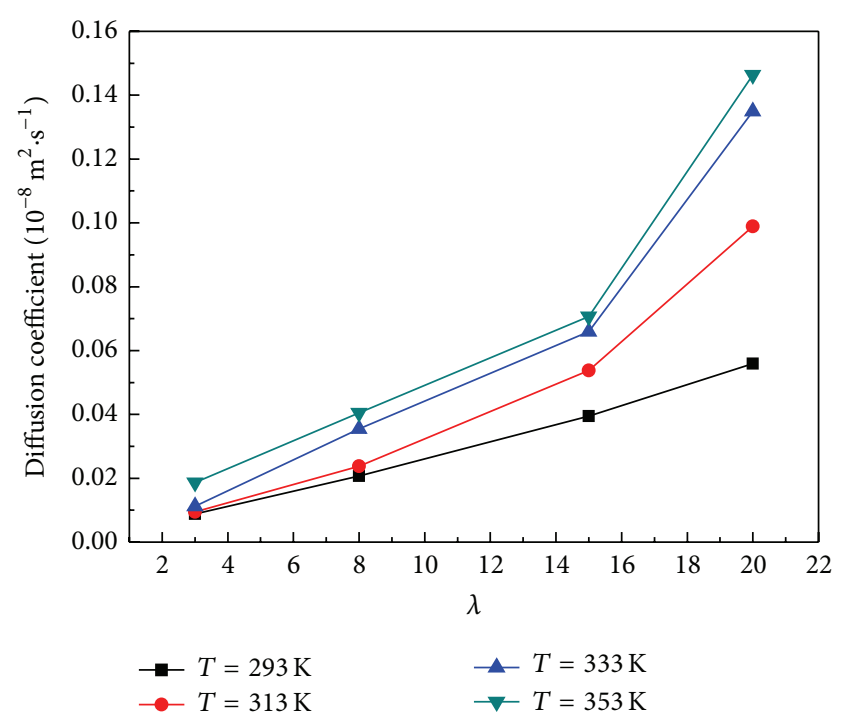

FIGURE 7: The variations in the diffusion coefficient of the hydrated ion with water content at different cell temperatures.

It is also shown in Figure 8 that the corresponding distances of the maximum RDF values of $\mathrm{O}_{2}-\mathrm{O}_{3}$ and $\mathrm{S}-\mathrm{O}_{3}$ barely change with the increase of the water content, while that of $\mathrm{O}_{2}-\mathrm{O}_{2}$ decreases. High water content compresses the space between the particles; however, it does not compress the internal space of the group with the binding force. For the free water molecule, the force between the water molecules may be too small to overcome the exerted force caused by increasing the water content; this results in the decrease of the distance between the two free water molecules. On the other hand, the internal forces of $\mathrm{O}_{2}-\mathrm{O}_{3}$ and $\mathrm{S}-\mathrm{O}_{3}$ are enough to overcome the external force exerted by increasing the water content. It is worth noting that the corresponding distance of the maximum RDF values of $\mathrm{O}_{3}-\mathrm{H}_{3}$ increases slightly with the increase of the water content from 3 to 15 . The possible explanation is that when the water content is low, each proton combines with one free water molecule and forms $\mathrm{H}_{3} \mathrm{O}^{+}$; with the increase of the water content, more and more protons combine with two or more free water molecules and form $\mathrm{H}^{+}\left(\mathrm{H}_{2} \mathrm{O}\right)_{n}$. Due to the addition of another free water molecule into $\mathrm{H}_{3} \mathrm{O}^{+}$, the bond energy of $\mathrm{O}_{3}-\mathrm{H}_{3}$ in $\mathrm{H}_{3} \mathrm{O}^{+}$is more than that in $\mathrm{H}^{+}\left(\mathrm{H}_{2} \mathrm{O}\right)_{n}$, and the bond length of $\mathrm{O}_{3}-\mathrm{H}_{3}$ in $\mathrm{H}_{3} \mathrm{O}^{+}$is shorter than that in $\mathrm{H}^{+}\left(\mathrm{H}_{2} \mathrm{O}\right)_{n}$.

\subsection{Effects of the Electric Field Intensity on the Transfer of the} Hydrated Ion. Generally, there is an electric field between the anode and the cathode in a PEM fuel cell due to the faster rate of electron transfer through the external circuit when compared to that of proton transfer through the Nafion membrane. To study the effects of the electric field on the performance of a fuel cell, an external electric field was applied between the anode and the cathode. Figure 9 shows these effects on the diffusion coefficient of the hydrated ion in Nafion 117 at different cell temperatures and a fixed water content of 8 . It is revealed that the hydrated ion diffusion coefficient increases with the increase of the electric field 

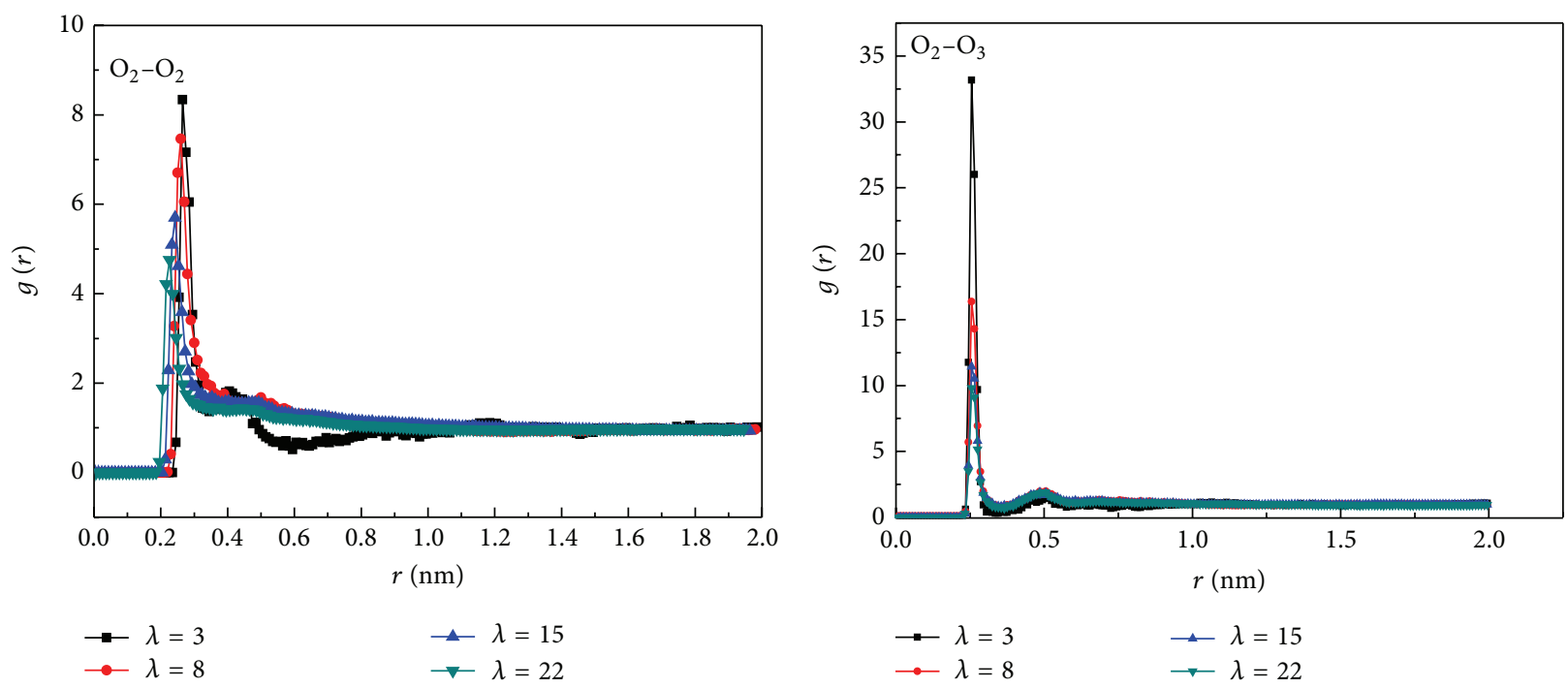

(a) $\mathrm{RDF}$ of $\mathrm{O}_{2}-\mathrm{O}_{2}$ with the water content
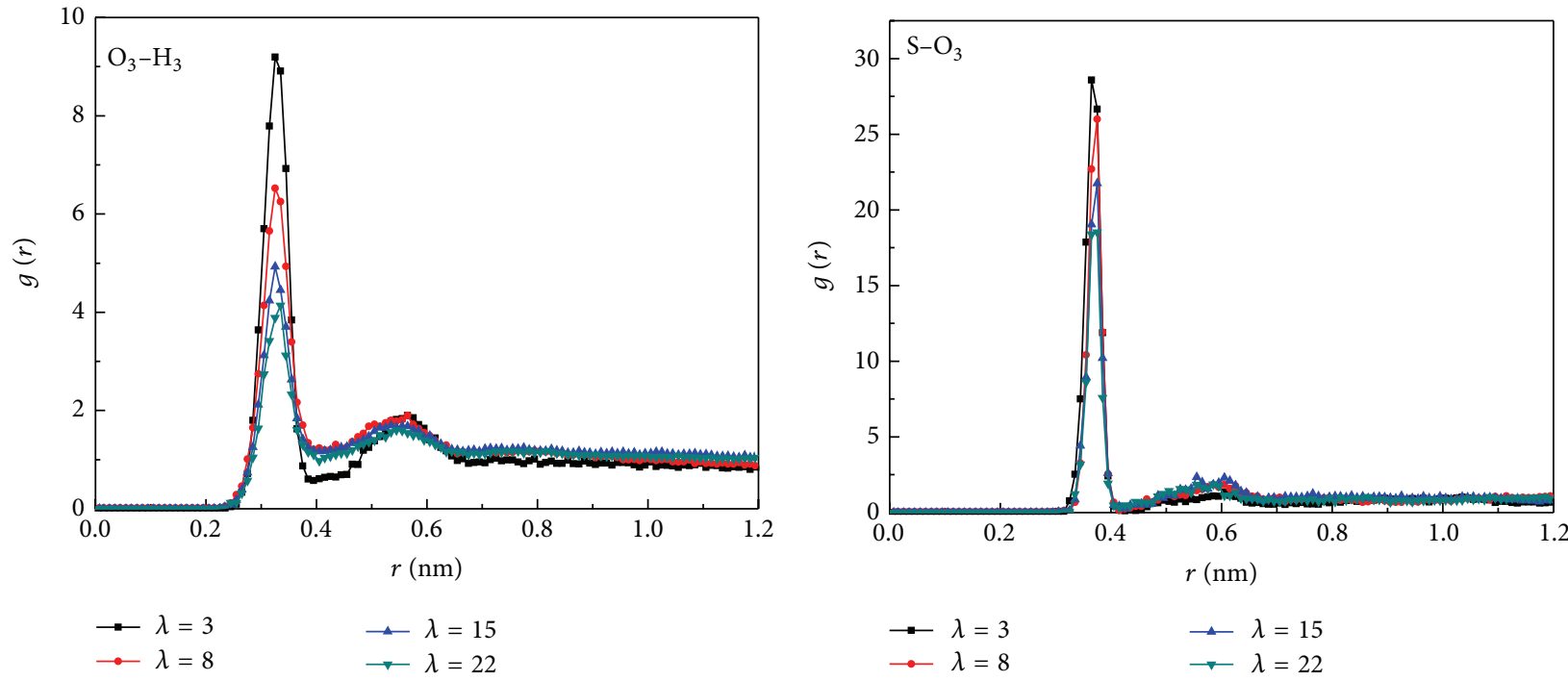

(c) $\mathrm{RDF}$ of $\mathrm{O}_{3}-\mathrm{H}_{3}$ with the water content

(d) $\mathrm{RDF}$ of $\mathrm{S}_{-} \mathrm{O}_{3}$ with the water content

FIGURE 8: The RDFs of different pairs of particles at different water contents with $T=333 \mathrm{~K}$ and $0 \mathrm{~V} \mathrm{~m}^{-1}$.

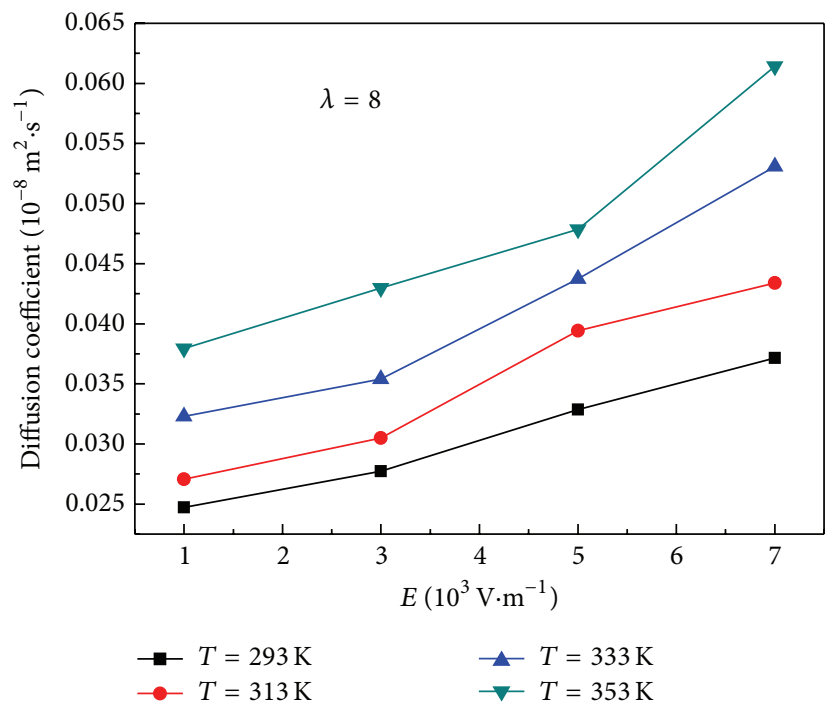

FIGURE 9: The variations in the diffusion coefficient of the hydrated ion with the electric field intensity at different cell temperatures and $\lambda=8$. 


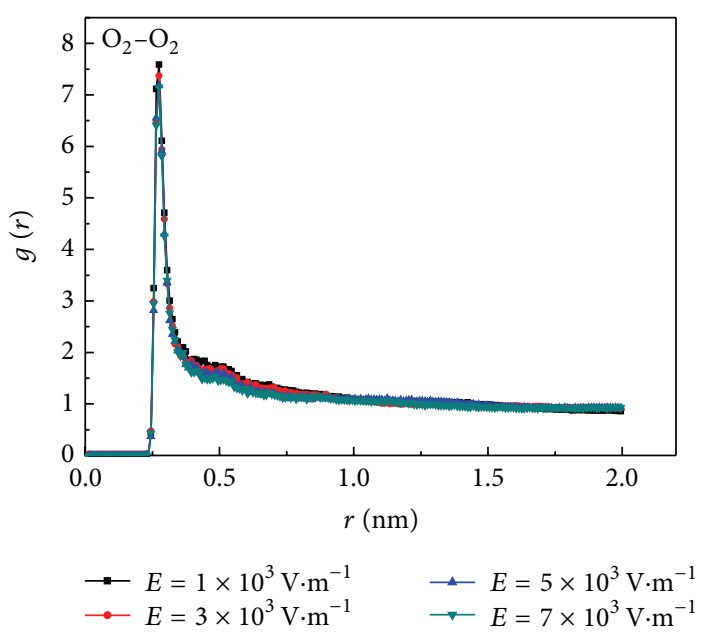

(a) $\mathrm{RDF}$ of $\mathrm{O}_{2}-\mathrm{O}_{2}$ with electric field intensity

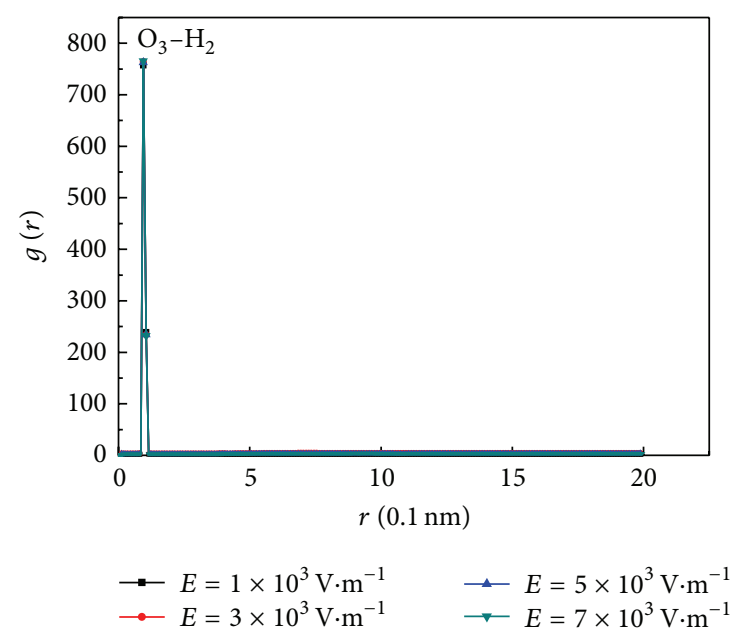

(c) $\mathrm{RDF}$ of $\mathrm{O}_{3}-\mathrm{H}_{2}$ with electric field intensity

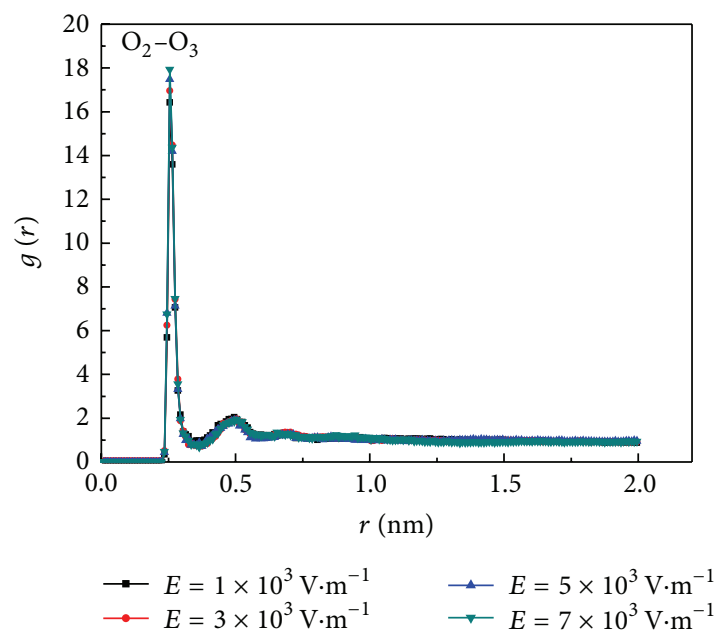

(b) $\mathrm{RDF}$ of $\mathrm{O}_{2}-\mathrm{O}_{3}$ with electric field intensity
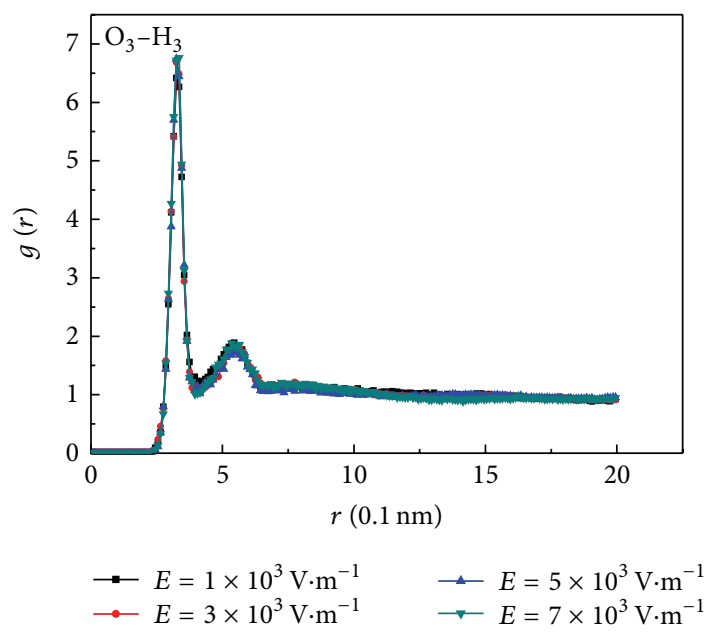

(d) $\mathrm{RDF}$ of $\mathrm{O}_{3}-\mathrm{H}_{3}$ with electric field intensity

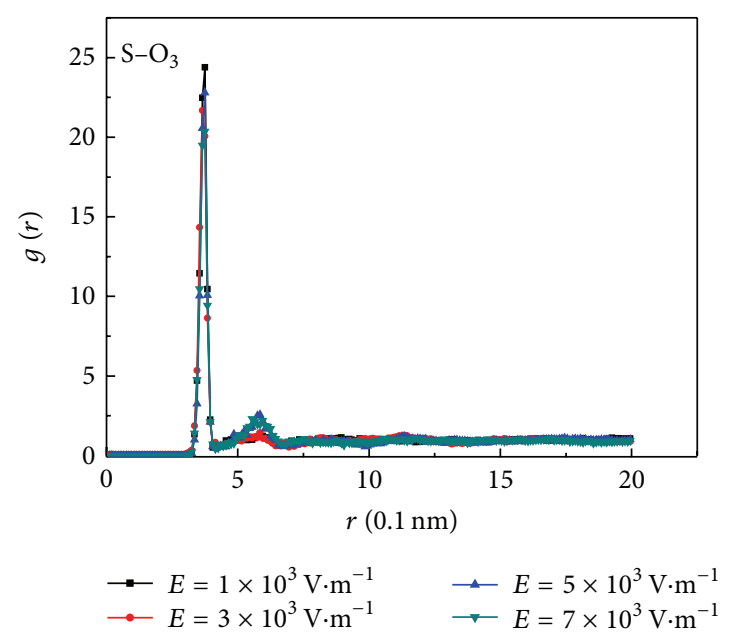

(e) $\mathrm{RDF}$ of $\mathrm{S}-\mathrm{O}_{3}$ with electric field intensity

FIGURE 10: The RDFs of different pairs of particles at different electric field intensities with $T=333 \mathrm{~K}$ and $\lambda=8$. 
intensity. It is well known that an electric field generates a driving force on a charged particle. Therefore, the electric field drives the movement of the hydrated ion in the direction of the imposed electric field. The larger the electric field intensity is, the greater the diving force on the hydrated ion is and the faster the hydrated ion movement is.

To further analyze the effects of the electric field on the transfer of the hydrated ion in the Nafion 117 membrane, the RDFs of $\mathrm{O}_{2}-\mathrm{O}_{2}, \mathrm{O}_{2}-\mathrm{O}_{3}, \mathrm{O}_{3}-\mathrm{H}_{3}, \mathrm{O}_{3}-\mathrm{H}_{2}$, and $\mathrm{S}-\mathrm{O}_{3}$ were calculated and the results are presented in Figure 10. In this figure, the temperature was fixed at $333 \mathrm{~K}$ and the water content was set to 8 . It is clear from this figure that the maximum value of the RDF and its corresponding distance were not affected by the imposed electric field for all pairs of particles, regardless of the amount applied. Since the free water molecule is electroneutral, imposing an electric field on the cell did not generate a driving force to move these molecules. For $\mathrm{O}_{2}-\mathrm{O}_{3}, \mathrm{O}_{3}-\mathrm{H}_{3}, \mathrm{O}_{3}-\mathrm{H}_{2}$, and $\mathrm{S}-\mathrm{O}_{3}$, these groups have enough internal force to overcome the external force exerted by the externally applied electric field.

By comparing and analyzing the results shown in Figures $4,6,8$, and 10 , it can be seen that the interaction force between two free water molecules is very small and the distribution of a free water molecule is affected by the operating temperature and the water content in the Nafion membrane; the internal forces in $\mathrm{O}_{2}-\mathrm{O}_{3}, \mathrm{O}_{3}-\mathrm{H}_{2}$, and $\mathrm{S}-\mathrm{O}_{3}$ groups are enough to overcome the external forces exerted by the high temperature, higher water content, and the imposed electric field; increasing the cell temperature and applying an electric field barely have an effect on the distance of $\mathrm{O}_{3}-$ $\mathrm{H}_{3}$. Moreover, the corresponding distance for the maximum $\mathrm{RDF}$ value of $\mathrm{O}_{3}-\mathrm{H}_{3}$ increases slightly with the increase of the water content from 3 to 15 , while it does not change with the increase of the water content from 15 to 22 .

Therefore, a very important conclusion can be obtained that when the water content in the Nafion 117 is low, the hydrated ion of $\mathrm{H}_{3} \mathrm{O}^{+}$is the main transfer particle; when the water content increases, the hydrated ion of $\mathrm{H}^{+}\left(\mathrm{H}_{2} \mathrm{O}\right)_{2}$ is the main transfer particle, while the $\mathrm{H}^{+}\left(\mathrm{H}_{2} \mathrm{O}\right)_{n>3}$ is not considered as hydrated ion group because of the very weak bond energy between the two free water molecules [13].

\section{Conclusions}

This paper presented a molecular dynamic model on the transfer of hydrated protons in Nafion 117 membranes. This model incorporated Lennard-Jones Potential, the interaction forces between two particles, molecular diffusion, and the RDFs of the mobile groups. In this simulation, NVT system, Andersen hot bath method, and Verlet leap-frog algorithm were used. The mechanisms involved with the transfer of the hydrated ion and how it is affected by the operating temperature, the water content, and the electric field were analyzed. The following conclusions can be made from the molecular simulation results.

(1) When the water content in Nafion 117 is low, among the different hydrated ions, $\mathrm{H}_{3} \mathrm{O}^{+}$is the main transfer particle. When the water content is high, the hydrated ion of $\mathrm{H}^{+}\left(\mathrm{H}_{2} \mathrm{O}\right)_{2}$ is the main transfer particle.

(2) High temperature promotes the diffusion of the hydrated ion in Nafion 117 due to enhancing of the movement and the vibration of the proton and its carrier.

(3) High water content also improves the diffusion of the hydrated ion owing to an increase in the number of proton carriers.

(4) The electric field drives the transfer of the hydrated ion by exerting a force on it and does not affect the radial distribution of all particles.

(5) The negatively charged sulfonic acid group as the fortified point facilitates the proton transfer in Nafion 117 better than the free water molecule.

\section{Conflict of Interests}

The authors declare that there is no conflict of interests regarding the publication of this paper.

\section{Acknowledgments}

The financial support from the National Natural Science Foundation of China (51176131, 51476107) and the Supporting Foundation of Liaoning Province Distinguished Visiting Professor of China is greatly appreciated.

\section{References}

[1] J. Karo, A. Aabloo, J. O. Thomas, and D. Brandell, "Molecular dynamics modeling of proton transport in nafion and hyflon nanostructures," Journal of Physical Chemistry B, vol. 114, no. 18, pp. 6056-6064, 2010.

[2] D. E. Moilanen, D. B. Spry, and M. D. Fayer, "Water dynamics and proton transfer in nafion fuel cell membranes," Langmuir, vol. 24, no. 8, pp. 3690-3698, 2008.

[3] Y.-K. Choe, E. Tsuchida, T. Ikeshoji, S. Yamakawa, and S.A. Hyodo, "Nature of water transport and electro-osmosis in nafion: insights from first-principles molecular dynamics simulations under an electric field," The Journal of Physical Chemistry B, vol. 112, no. 37, pp. 11586-11594, 2008.

[4] H. Sun, Z. Sun, and Y. Wu, "Proton transfer mechanism in perfluorinated sulfonic acid polytetrafluoroethylene," International Journal of Hydrogen Energy, vol. 37, no. 17, pp. 12821-12826, 2012.

[5] C. K. Knox and G. A. Voth, "Probing selected morphological models of hydrated nafion using large-scale molecular dynamics simulations," The Journal of Physical Chemistry B, vol. 114, no. 9, pp. 3205-3218, 2010.

[6] K.-D. Kreuer, S. J. Paddison, E. Spohr, and M. Schuster, "Transport in proton conductors for fuel-cell applications: simulations, elementary reactions, and phenomenology," Chemical Reviews, vol. 104, no. 10, pp. 4637-4678, 2004.

[7] P. Choi, N. H. Jalani, and R. Datta, "Thermodynamics and proton transport in Nafion II. Proton diffusion mechanisms and conductivity," Journal of the Electrochemical Society, vol. 152, no. 3, pp. E123-E130, 2005. 
[8] S. Cui, J. Liu, M. E. Selvan, D. J. Keffer, B. J. Edwards, and W. V. Steele, "A molecular dynamics study of a nafion polyelectrolyte membrane and the aqueous phase structure for proton transport," The Journal of Physical Chemistry B, vol. 111, no. 9, pp. 2208-2218, 2007.

[9] A. Venkatnathan, R. Devanathan, and M. Dupuis, "Atomistic simulations of hydrated nafion and temperature effects on hydronium ion mobility," The Journal of Physical Chemistry B, vol. 111, no. 25, pp. 7234-7244, 2007.

[10] J. R. P. Jayakody, P. E. Stallworth, E. S. Mananga, J. FarringtonZapata, and S. G. Greenbaum, "High pressure NMR study of water self-diffusion in NAFION-117 membrane," Journal of Physical Chemistry B, vol. 108, no. 14, pp. 4260-4262, 2004.

[11] R. Jinnouchi and K. Okazaki, "Molecular dynamics study of transport phenomena in perfluorosulfonate ionomer membranes for polymer electrolyte fuel cells," Journal of the Electrochemical Society, vol. 150, no. 1, pp. E66-E73, 2003.

[12] J. Han, X. Zhou, and H. Liu, "Ab initio simulation on the mechanism of proton transport in water," Journal of Power Sources, vol. 161, no. 2, pp. 1420-1427, 2006.

[13] P. Intharathep, A. Tongraar, and K. Sagarik, "Ab initio QM/MM dynamics of $\mathrm{H}_{3} \mathrm{O}^{+}$in water," Journal of Computational Chemistry, vol. 27, no. 14, pp. 1723-1732, 2006.

[14] M. Kaledin, A. L. Kaledin, and J. M. Bowman, "Vibrational analysis of the $\mathrm{H}_{5} \mathrm{O}_{2}^{+}$infrared spectrum using molecular and driven molecular dynamics," Journal of Physical Chemistry A, vol. 110, no. 9, pp. 2933-2939, 2006.

[15] O. Markovitch and N. Agmon, "Structure and energetics of the hydronium hydration shells," The Journal of Physical Chemistry A, vol. 111, no. 12, pp. 2253-2256, 2007.

[16] R. Devanathan, A. Venkatnathan, and M. Dupuis, "Atomistic simulation of nafion membrane. 2. dynamics of water molecules and hydronium ions," The Journal of Physical Chemistry B, vol. 111, no. 45, pp. 13006-13013, 2007.

[17] K. Sagarik, M. Phonyiem, C. Lao-Ngam, and S. Chaiwongwattana, "Mechanisms of proton transfer in Nafion: elementary reactions at the sulfonic acid groups," Physical Chemistry Chemical Physics, vol. 10, no. 15, pp. 2098-2112, 2008.

[18] D. W. M. Hofmann, L. Kuleshova, B. D’Aguanno et al., "Investigation of water structure in Nafion membranes by infrared spectroscopy and molecular dynamics simulation," The Journal of Physical Chemistry B, vol. 113, no. 3, pp. 632-639, 2009.

[19] D. R. Morris and X. Sun, "Water-sorption and transport properties of Nafion 117 H," Journal of Applied Polymer Science, vol. 50, no. 8, pp. 1445-1452, 1993.

[20] E. Spohr, "Molecular dynamics simulations of Proton transfer in a model nafion pore," Molecular Simulation, vol. 30, no. 2-3, pp. 107-115, 2004.

[21] D. B. Spry, A. Goun, K. Glusac, D. E. Moilanen, and M. D. Fayer, "Proton transport and the water environment in Nafion fuel cell membranes and AOT reverse micelles," Journal of the American Chemical Society, vol. 129, no. 26, pp. 8122-8130, 2007.

[22] J. J. Sumner, S. E. Creager, J. J. Ma, and D. D. DesMarteau, "Proton conductivity in nafion 117 and in a novel bis[(perfluoroalkyl)sulfonyl]imide ionomer membrane," Journal of the Electrochemical Society, vol. 145, no. 1, pp. 107-110, 1998.

[23] B. D. Cahan and J. S. Wainright, "AC impedance investigations of proton conduction in NafionTM," Journal of the Electrochemical Society, vol. 140, no. 12, pp. L185-L186, 1993.

[24] D. B. Spry and M. D. Fayer, "Proton transfer and proton concentrations in protonated nafion fuel cell membranes,"
Journal of Physical Chemistry B, vol. 113, no. 30, pp. 10210-10221, 2009.

[25] E. L. Thompson, T. W. Capehart, T. J. Fuller, and J. Jorne, "Investigation of low-temperature proton transport in nafion using direct current conductivity and differential scanning calorimetry," Journal of the Electrochemical Society, vol. 153, no. 12, pp. A2351-A2362, 2006.

[26] P. W. Majsztrik, M. B. Satterfield, A. B. Bocarsly, and J. B. Benziger, "Water sorption, desorption and transport in Nafion membranes," Journal of Membrane Science, vol. 301, no. 1-2, pp. 93-106, 2007.

[27] M. E. Selvan, Q. He, E. M. Calvo-Muñoz, and D. J. Keffer, "Molecular dynamic simulations of the effect on the hydration of nafion in the presence of a platinum nanoparticle," The Journal of Physical Chemistry C, vol. 116, no. 23, pp. 12890-12899, 2012.

[28] L. Yan, X. Ji, and W. Lu, "Molecular dynamics simulations of electroosmosis in perfluorosulfonic acid polymer," Journal of Physical Chemistry B, vol. 112, no. 18, pp. 5602-5610, 2008.

[29] D. Brandell, J. Karo, A. Liivat, and J. O. Thomas, "Molecular dynamics studies of the Nafion, Dow and Aciplex fuel-cell polymer membrane systems," Journal of Molecular Modeling, vol. 13, no. 10, pp. 1039-1046, 2007. 

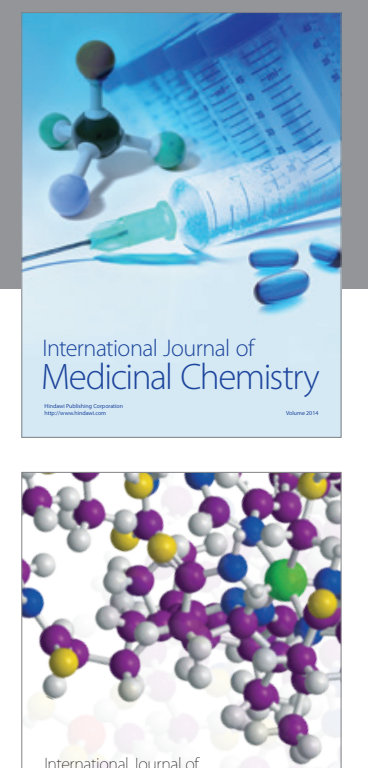

\section{Carbohydrate} Chemistry

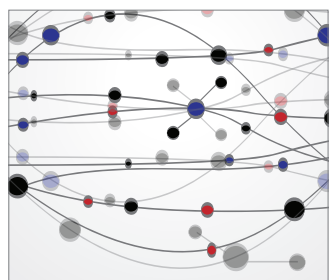

The Scientific World Journal
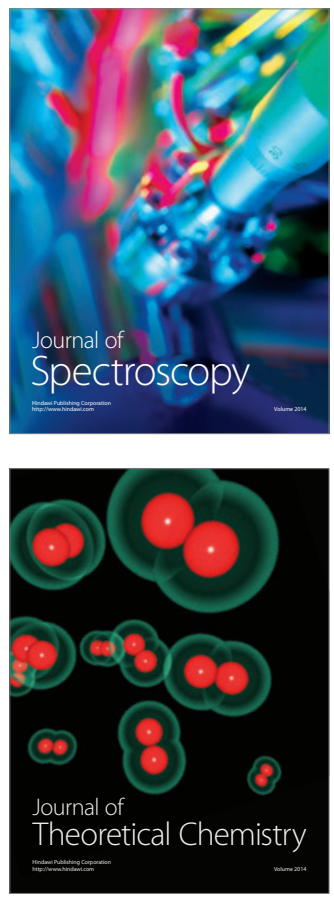
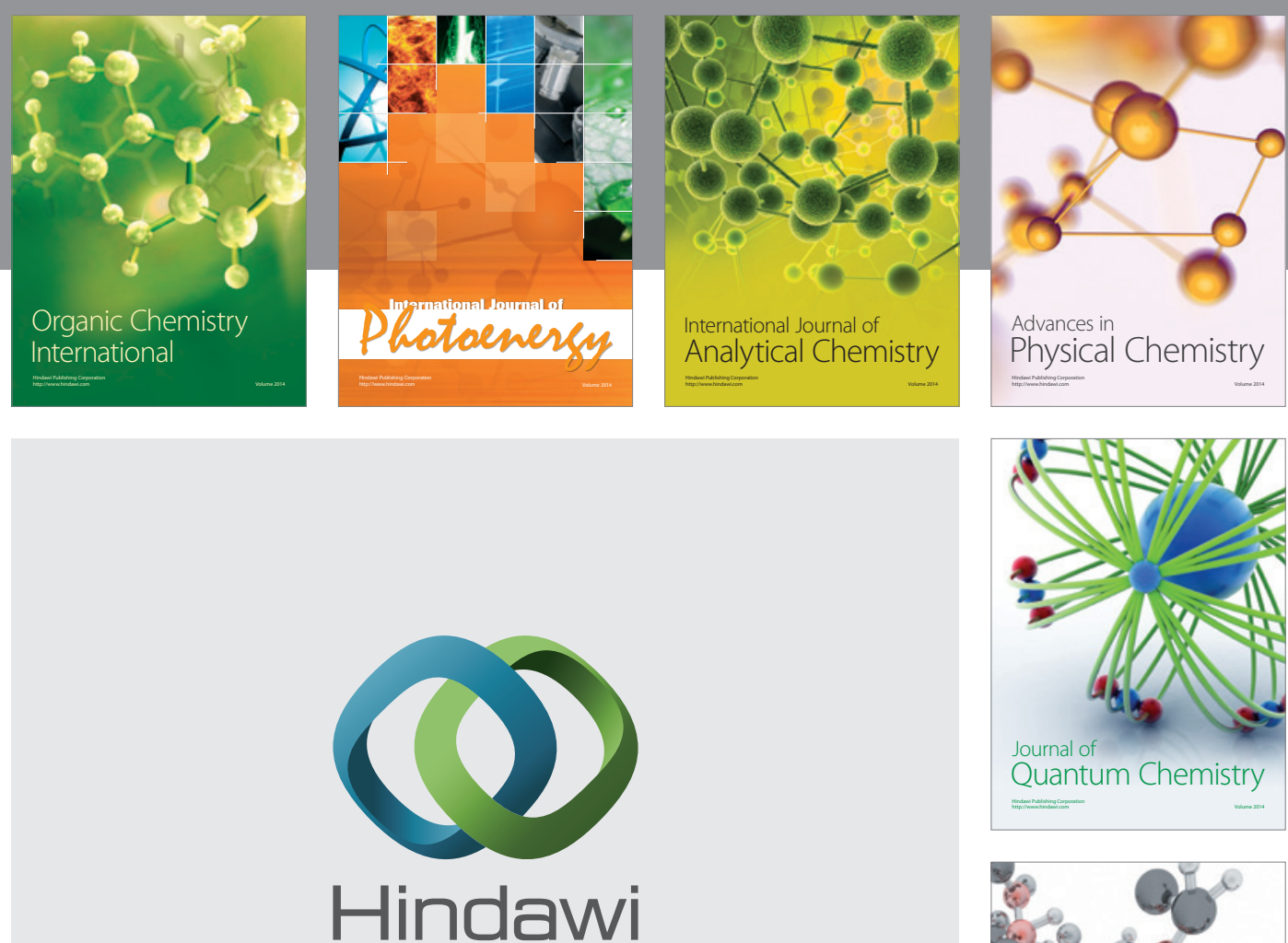

Submit your manuscripts at

http://www.hindawi.com

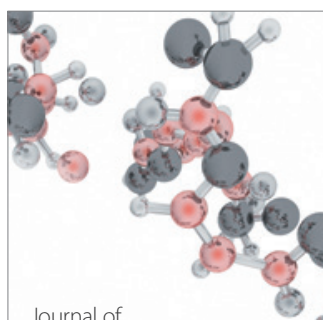

Analytical Methods

in Chemistry

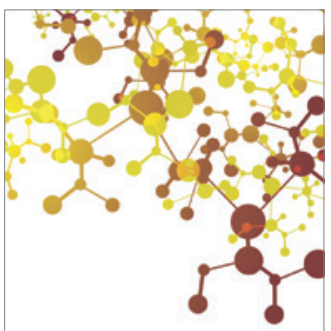

Journal of

Applied Chemistry

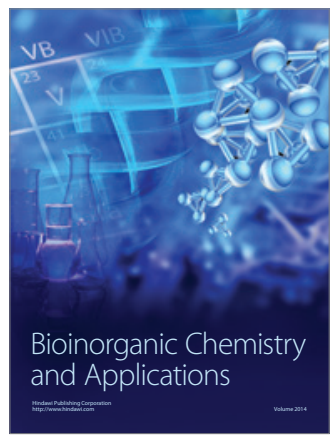

Inorganic Chemistry
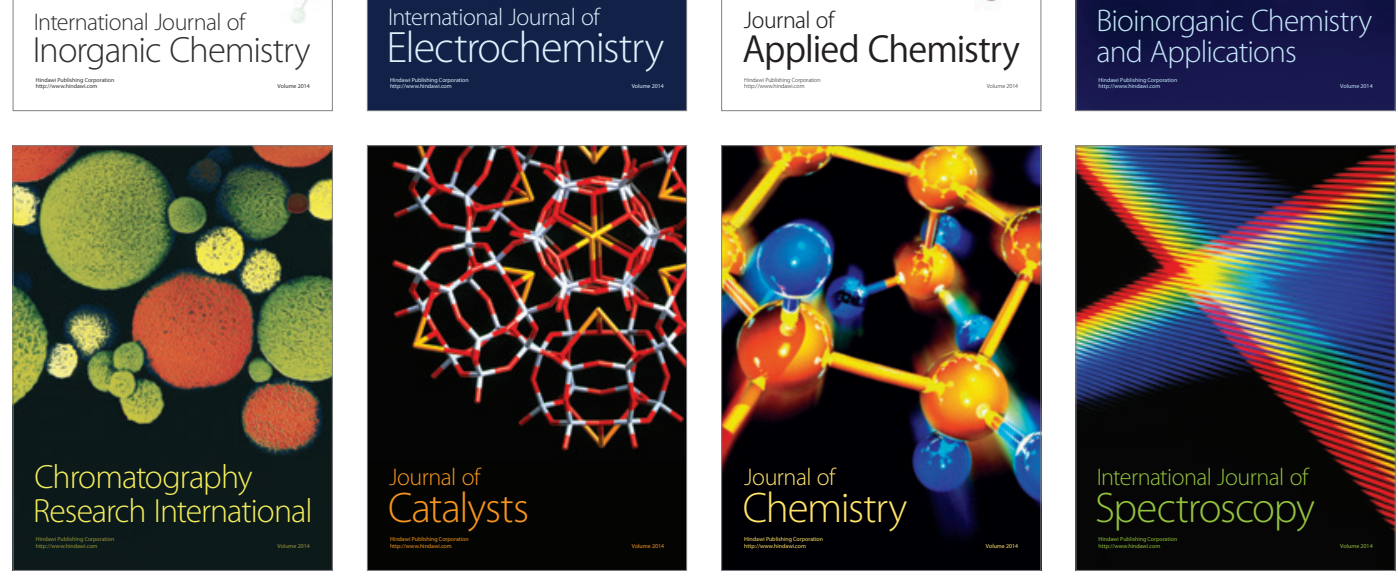